\title{
Efficacy of Zoladex LA (goserelin) in the treatment of girls with central precocious or early puberty
}

\author{
W F Paterson, E McNeill, S Reid, A S Hollman, M D C Donaldson
}

\begin{abstract}
Objective-To assess the efficacy of a longer acting preparation of the gonadotrophin releasing hormone (GnRH) analogue goserelin (Zoladex LA, $10.8 \mathrm{mg}$ ) in 12 girls with central precocious or early puberty.

Methods-Two girls started treatment de novo; the remainder had been on suppressive treatment for a median duration of 1.5 (range, 0.2-5.6) years. Assessment comprising auxology, pubertal staging, and pelvic ultrasound examination was carried out at weeks $0,4,8,10$, and 12 (first cycle) and weeks 8,10 , and 12 (second cycle) to evaluate the required injection frequency. Thereafter, assessment was performed on the day of injection. Zoladex LA was given every 12 weeks unless pubertal progression occurred.

Results-Satisfactory control was achieved in eight patients using this regimen, and three patients required more frequent injections. One girl was removed from the study because of clinical progression and extreme mood swings. No serious adverse effects occurred. Mean height velocity during the study period was $4.5 \mathrm{~cm} /$ year (range, 3.1-6.6) compared with $6.5 \mathrm{~cm} /$ year (range, 3.8-9.6) before treatment in nine patients for whom data were available.

Conclusions-Zoladex LA was effective in controlling precocious puberty in girls when given at intervals of 9-12 weeks and it is recommended that an initial assessment is made eight weeks after beginning treatment.

(Arch Dis Child 1998;79:323-327)
\end{abstract}

Department of Child Health, Royal Hospital for Sick Children,

Yorkhill, Glasgow

G3 8SJ, UK

W F Paterson

E McNeill

M D C Donaldson

Department of Diagnostic Imaging, Royal Hospital for Sick

Children

$S$ Reid

A S Hollman

Correspondence to: Dr Donaldson.

Accepted 12 May 1998 steroids. ${ }^{2}{ }^{3}$ The first GnRH analogues ave able needed to be given either by daily subcutaneous injection or intranasally. Exam- ples include buserelin (Hoechst), nafarelin (Searle; Syntex), histrelin (Ortho), and deslorelin (Roberts). It has been reported that intranasal preparations give incomplete gonadotrophin suppression ${ }^{4}$ and because they need to be given four times a day compliance is difficult to achieve. These preparations have largely been superseded by long acting depot preparations, given by intramuscular or subcutaneous injection, usually on a monthly basis - for example, leuprolide (Wyeth, Berks, UK; TAP), triptorelin (Speywood; Ferring), and goserelin (Zeneca).

Goserelin, in the form of a $3.6 \mathrm{mg}$ depot preparation (Zoladex), has been particularly successful. ${ }^{5-7}$ This preparation is administered by subcutaneous injection into the anterior abdominal wall, and is generally efficacious when given at intervals of three or four weeks. A longer acting formulation of goserelin (Zoladex LA; $10.8 \mathrm{mg}$ biodegradable depot; Zeneca, Cheshire, UK) has become available recently. Because this product is three times the dose of the standard preparation, a reduced injection frequency can be anticipated. Our study was undertaken to assess the efficacy of Zoladex LA in girls with early or precocious puberty, and the optimum injection frequency required to achieve pubertal suppression.

\section{Patients and methods}

\section{PATIENTS}

Our study group comprised girls with central precocious or early puberty, defined as "precocious" if onset of symptoms was before age 8 years and "early" if between the ages of 8 and 10 years. The diagnosis was based on the history of pubertal symptoms and signs, increased height velocity, and bone age advance, and was confirmed by pelvic ultrasonography and luteinising hormone releasing hormone (LHRH) stimulation test $(100 \mu \mathrm{g} \mathrm{HRF}$; Monmouth Pharmaceuticals, Surrey, UK). Pelvic ultrasound findings were compared with the standards described by Griffin et al, ${ }^{8}$ (table 1) while a pubertal response to LHRH was defined as peak $\mathrm{LH}>5.0 \mathrm{U} / 1$. Girls with specific pathology affecting the hypothalamopituitary axis-for example, intracranial neoplasm or previous cranial irradiation, were excluded.

\section{TREATMENT}

Treatment was with GnRH analogue only. The anti-androgen, cyproterone acetate, which can be given to counteract the initial stimulatory effect of GnRH analogue treatment, ${ }^{9}$ was not 
Table 1 Normal values for uterine length and ovarian volumes during childhood

\begin{tabular}{llll}
\hline Age (years) & Uterine length $(\mathrm{cm})$ & Right ovary volume $\left(\mathrm{cm}^{3}\right)$ & Left ovary volume $\left(\mathrm{cm}^{3}\right)$ \\
\hline 5.0 & $2.6(1.55-3.65)$ & $0.75(0.2-2.55)$ & $0.6(0.2-2.4)$ \\
6.0 & $2.7(1.55-3.85)$ & $0.85(0.25-3.0)$ & $0.7(0.2-2.9)$ \\
7.0 & $2.85(1.6-4.15)$ & $1.0(0.2-3.4)$ & $0.8(0.25-3.35)$ \\
8.0 & $3.1(1.7-4.5)$ & $1.15(0.35-4.0)$ & $1.0(0.3-3.95)$ \\
9.0 & $3.4(1.8-4.9)$ & $1.35(0.4-4.6)$ & $1.15(0.35-4.6)$ \\
10.0 & $3.75(2.1-5.4)$ & $1.55(0.5-5.3)$ & $1.35(0.4-5.4)$ \\
11.0 & $4.15(2.3-6.0)$ & $1.8(0.5-6.2)$ & $1.6(0.45-6.4)$ \\
12.0 & $4.65(2.7-6.6)$ & $2.1(0.6-7.2)$ & $1.8(0.5-7.5)$ \\
13.0 & $5.2(3.1-7.3)$ & $2.4(0.7-8.3)$ & $2.2(0.6-8.9)$ \\
\hline
\end{tabular}

Values are mean (range 3rd-97th centiles), transcribed from the centile charts of Griffin et al. ${ }^{8}$

Table 2 Pelvic ultrasound results and breast stages for patient 1

\begin{tabular}{|c|c|c|c|c|c|c|c|}
\hline & \multicolumn{7}{|c|}{ Cycle of Zoladex $L A$ treatment } \\
\hline & 0 & 1 & 2 & $3^{\star}$ & 4 & 5 & 6 \\
\hline Age (years) & 8.4 & & & 9.1 & & & 9.6 \\
\hline Breast stage & 1 & 1 & - & 1 & 1 & 1 & 1 \\
\hline Uterine shape & $\mathrm{C}$ & $\mathrm{C}$ & $\mathrm{C}$ & $\mathrm{P}$ & I & $\mathrm{C}$ & $\mathrm{C}$ \\
\hline Uterine length $(\mathrm{cm})$ & 4.2 & 4.0 & 3.3 & 5.6 & 4.4 & 3.1 & 2.8 \\
\hline Endometrial echo (mm) & - & - & - & 1.0 & - & - & - \\
\hline Right ovary volume $\left(\mathrm{cm}^{3}\right)$ & 4.4 & 2.9 & 2.7 & 6.5 & 3.9 & 0.6 & 1.1 \\
\hline Left ovary volume $\left(\mathrm{cm}^{3}\right)$ & 2.0 & 2.2 & 2.7 & 3.8 & 1.0 & 0.4 & 2.1 \\
\hline
\end{tabular}

Zoladex LA injections were given every 12 weeks.

${ }^{\star}$ Changed to injections every nine weeks.

I, infantile (cervix larger than fundus); C, cylindrical (mid-childhood shape with cervix and fundus approximately the same); P, pear shaped (adult shape with fundus larger than cervix).

Table 3 Pelvic ultrasound results and breast stages for patient 2

\begin{tabular}{lllllll}
\hline \multicolumn{7}{l}{ Cycle of Zoladex LA treatment } \\
\cline { 2 - 7 } & 0 & 1 & 2 & 3 & 4 & 5 \\
\hline Age (years) & 8.2 & & & & & 9.3 \\
Breast stage & $1+$ & 1 & 1 & $1+$ & $1+$ & $1+$ \\
Uterine shape & $\mathrm{C}$ & $\mathrm{C}$ & $\mathrm{C}$ & $\mathrm{C}$ & $\mathrm{C}$ & $\mathrm{C}$ \\
Uterine length $(\mathrm{cm})$ & 3.2 & 2.7 & 3.6 & 3.4 & 2.6 & 2.9 \\
Endometrial echo $(\mathrm{mm})$ & - & - & - & - & - & - \\
Right ovary volume $\left(\mathrm{cm}^{3}\right)$ & 4.2 & 4.2 & 1.2 & 2.9 & 1.0 & 1.9 \\
Left ovary volume $\left(\mathrm{cm}^{3}\right)$ & 3.0 & 1.9 & 1.1 & 1.5 & 1.1 & 1.7 \\
\hline
\end{tabular}

Zoladex LA injections were given every 12 weeks.

$\mathrm{C}$, cylindrical (mid-childhood shape with cervix and fundus approximately the same).

Table 4 Pelvic ultrasound results and breast stages for patient 3

\begin{tabular}{llllllll}
\hline & \multicolumn{7}{l}{ Cycle of Zoladex LA treatment } \\
\cline { 2 - 9 } & 0 & 1 & 2 & 3 & 4 & 5 & 6 \\
\hline Age (years) & 9.7 & & & & & & 11.1 \\
Breast stage & 2 & 2 & 2 & 2 & 2 & 2 & 2 \\
Uterine shape & $\mathrm{C}$ & $\mathrm{C}$ & $\mathrm{C}$ & $\mathrm{P}$ & $\mathrm{C}$ & $\mathrm{C}$ & $\mathrm{C}$ \\
Uterine length (cm) & 3.2 & 3.3 & 3.7 & 3.9 & 2.8 & 3.3 & 3.3 \\
Endometrial echo $(\mathrm{mm})$ & - & 1.2 & 1.1 & - & - & - & - \\
Right ovary volume $\left(\mathrm{cm}^{3}\right)$ & 0.7 & 2.5 & 1.3 & 2.9 & 0.8 & 2.4 & 2.4 \\
Left ovary volume $\left(\mathrm{cm}^{3}\right)$ & 1.0 & 1.8 & 1.3 & 1.6 & 0.7 & 1.4 & 1.4 \\
\hline
\end{tabular}

Zoladex LA injections were given every 12 weeks.

C, cylindrical (mid-childhood shape with cervix and fundus approximately the same); P, pear shaped (adult shape with fundus larger than cervix).

Table 5 Pelvic ultrasound results and breast stages for patient 4

\begin{tabular}{llllllll}
\hline & \multicolumn{7}{l}{ Cycle of Zoladex LA treatment } \\
\cline { 2 - 9 } & 0 & 1 & 2 & 3 & 4 & 5 & 6 \\
\hline Age (years) & 5.5 & & & & & & 6.9 \\
Breast stage & 2 & 2 & 2 & 2 & 2 & 2 & 3 \\
Uterine shape & $\mathrm{C}$ & $\mathrm{C}$ & $\mathrm{P}$ & $\mathrm{I}$ & $\mathrm{I}$ & $\mathrm{I}$ & $\mathrm{I}$ \\
Uterine length (cm) & 2.6 & 3.4 & 3.0 & 3.4 & 3.0 & 3.4 & 3.3 \\
Endometrial echo $(\mathrm{mm})$ & - & - & - & - & - & - & - \\
Right ovary volume $\left(\mathrm{cm}^{3}\right)$ & 1.6 & 1.9 & 1.7 & 1.2 & 2.1 & 1.9 & 1.8 \\
Left ovary volume $\left(\mathrm{cm}^{3}\right)$ & 1.8 & 1.4 & 1.3 & 3.0 & 1.3 & 1.3 & 2.1 \\
\hline
\end{tabular}

Zoladex LA injections were given every 12 weeks.

$\mathrm{I}$, infantile (cervix larger than fundus); C, cylindrical (mid-childhood shape with cervix and fundus approximately the same); P, pear shaped (adult shape with fundus larger than cervix). indicated in 10 of the 12 girls who were already being treated with an analogue. In the remaining two girls, we decided not to use cyproterone acetate in case it resulted in the known adverse effects of fatigue and depression.

Long acting goserelin (Zoladex LA, $10.8 \mathrm{mg}$ biodegradable depot; Zeneca) was given initially at 12 week intervals, by subcutaneous injection into the anterior abdominal wall. In most cases, the injection was given by the endocrine nurse specialist in hospital, after the application of a local anaesthetic cream (lignocaine $25 \mathrm{mg} /$ prilocaine $25 \mathrm{mg} / \mathrm{g}$; EMLA; Astra). In a few cases, the child's family practitioner gave the treatment. A play leader was used to provide distraction in the few instances where the girls became distressed at the time of injection.

MONITORING

Evaluation was carried out at zero, four, eight, 10 , and 12 weeks (first treatment cycle) and eight, 10, and 12 weeks (second treatment cycle) to determine the required injection frequency. Thereafter, each girl was assessed on the day of injection. Assessment comprised: - Auxology: height and weight each time, bone age annually according to the TW2 (RUS) method ${ }^{10}$

- Pubertal staging: breast, axillary hair, and pubic hair (according to the system of Tanner ${ }^{11}$ )

- Pelvic ultrasound: uterine length and configuration, fundo-cervical ratio, ovarian volumes and number, size of follicles, and endometrial echo. ${ }^{812}$

Uterine shape was designated as follows: I, infantile (cervix larger than fundus); C, cylindrical (mid-childhood shape with cervix and fundus approximately the same); P, pear shaped (adult shape with fundus larger than cervix).

Measurement of gonadotrophin and oestradiol levels was not carried out because this was considered to be unnecessarily invasive. Also, we have previously found gonadotrophin suppression in some girls on $\mathrm{GnRH}$ analogue treatment despite ultrasonic evidence of inadequate control (Donaldson MDC, unpublished data 1993).

\section{CRITERIA FOR ADEQUACY OF SUPPRESSIVE} TREATMENT

Efficacy of treatment was determined primarily by growth rate, breast stage, and uterine and ovarian morphology. In addition, the following signs and symptoms were also noted and taken into consideration:

- Deterioration in behaviour (for example, irritability and mood swings), especially if related to the one to two weeks preceding the next injection

- Cyclical abdominal pain

- Vaginal discharge

- Adult body odours.

Control was considered inadequate if the following criteria were met:

- Vaginal bleeding and/or more than one of the following adverse ultrasound features: 
Table 6 Pelvic ultrasound results and breast stages for patient 5

\begin{tabular}{lllllllll}
\hline \multicolumn{1}{c}{ Cycle of Zoladex LA treatment } \\
\cline { 2 - 9 } & 0 & 1 & 2 & 3 & 4 & 5 & 6 & 7 \\
\hline Age (years) & 5.1 & & & & & & & 6.3 \\
Breast stage & 2 & $2+$ & $2+$ & 2 & 2 & 2 & 2 & $2+$ \\
Uterine shape & $\mathrm{C}$ & $\mathrm{P}$ & $\mathrm{C}$ & $\mathrm{C}$ & $\mathrm{C}$ & $\mathrm{C}$ & $\mathrm{C}$ & $\mathrm{P}$ \\
Uterine length (cm) & 3.0 & 4.7 & 4.6 & 3.0 & 2.4 & 3.6 & 3.0 & 3.5 \\
Endometrial echo (mm) & - & 2.6 & - & - & - & - & - & - \\
Right ovary volume $\left(\mathrm{cm}^{3}\right)$ & 1.1 & 2.7 & 15.5 & 1.4 & 1.1 & 1.6 & 2.3 & 3.4 \\
Left ovary volume $\left(\mathrm{cm}^{3}\right)$ & 1.8 & 1.3 & 3.8 & 2.6 & 2.0 & 2.0 & 1.6 & 1.0 \\
\hline
\end{tabular}

Zoladex LA injections were given every 10 weeks for the first cycle only, then every nine weeks. $\mathrm{C}$, cylindrical (mid-childhood shape with cervix and fundus approximately the same); P, pear shaped (adult shape with fundus larger than cervix).

Table 7 Pelvic ultrasound results and breast stages for patient 6

\begin{tabular}{llllllll}
\hline \multicolumn{7}{c}{ Cycle of Zoladex } & LA treatment \\
\cline { 2 - 9 } & 0 & 1 & 2 & 3 & 4 & 5 & 6 \\
\hline Age (years) & 8.3 & & & & & & 9.7 \\
Breast stage & $2+$ & $2+$ & 2 & 2 & 2 & $2+$ & $2+$ \\
Uterine shape & $\mathrm{P}$ & $\mathrm{C}$ & $\mathrm{C}$ & $\mathrm{C}$ & $\mathrm{C}$ & $\mathrm{C}$ & $\mathrm{C}$ \\
Uterine length (cm) & 4.2 & 5.3 & 4.2 & 4.8 & 4.5 & 4.2 & 3.2 \\
Endometrial echo $(\mathrm{mm})$ & 3.1 & - & - & - & - & - & - \\
Right ovary volume $\left(\mathrm{cm}^{3}\right)$ & 2.9 & 3.8 & 2.1 & 9.7 & 0.3 & 2.6 & 0.8 \\
Left ovary volume $\left(\mathrm{cm}^{3}\right)$ & 3.6 & 2.0 & 2.1 & 5.6 & 0.3 & 1.7 & 1.0 \\
\hline
\end{tabular}

Zoladex LA injections were given every 12 weeks.

C, cylindrical (mid-childhood shape with cervix and fundus approximately the same); P, pear shaped (adult shape with fundus larger than cervix).

Table 8 Pelvic ultrasound results and breast stages for patient 7

\begin{tabular}{lllllll}
\hline & \multicolumn{7}{l}{ Cycle of Zoladex } & LA treatment \\
\cline { 2 - 7 } & 0 & 1 & 2 & 3 & 4 & 5 \\
\hline Age (years) & 9.3 & & & & & 10.5 \\
Breast stage & $2+$ & $2+$ & $3+$ & 3 & 3 & 3 \\
Uterine shape & $\mathrm{C}$ & $\mathrm{C}$ & $\mathrm{C}$ & $\mathrm{C}$ & $\mathrm{C}$ & $\mathrm{C}$ \\
Uterine length $(\mathrm{cm})$ & 4.1 & 3.9 & 3.8 & 4.6 & 4.5 & 4.3 \\
Endometrial echo $\left(\mathrm{mm}^{3}\right)$ & - & - & - & - & - & - \\
Right ovary volume $\left(\mathrm{cm}^{3}\right)$ & 1.1 & 0.8 & 1.4 & 1.3 & 0.8 & 1.2 \\
Left ovary volume $\left(\mathrm{cm}^{3}\right)$ & 0.8 & 2.2 & 2.1 & 0.7 & 0.7 & 1.7 \\
\hline
\end{tabular}

Zoladex LA injections were given every 12 weeks.

$\mathrm{C}$, cylindrical (mid-childhood shape with cervix and fundus approximately the same).

- increased uterine length/maturation, increased ovarian volume, presence of endometrial echo with or without any of the following:

- persistent progression of breast development

- increased height velocity

- any of the minor signs and symptoms listed above.

\section{Results}

Twelve girls were studied, five with early puberty and seven with precocious puberty. Initial diagnosis was confirmed by the LHRH test in 11 of the 12 girls, with a mean peak LH of 35.6 (range, 8.0-87.7) U/l. One girl (patient 1) had a peak LH of $4.5 \mathrm{U} / 1$ on presentation, but was considered to be in the early stages of true precocious puberty in view of her rapidly progressing clinical signs, advanced uterine and ovarian development, and response to treatment with GnRH analogue. Uterine development was advanced for age in 11 girls (10 of whom had a midline endometrial echo), and ovarian development was advanced in eight girls. Mean bone age advancement was 2.4 (range, 0.9-4.4) years. The condition was idiopathic in nine girls and associated with learning difficulties in three girls (one autism, one William's syndrome, and one unclassified).
Table 9 Pelvic ultrasound results and breast stages for patient 8

\begin{tabular}{lllll}
\hline & \multicolumn{4}{c}{ Cycle of Zoladex } \\
\cline { 2 - 5 } & 0 & 1 & 2 & 3 \\
\hline Age (years) & 10.4 & & & 11.0 \\
Breast stage & $2+$ & $3+$ & $3+$ & $3+$ \\
Uterine shape & $\mathrm{P}$ & $\mathrm{P}$ & $\mathrm{C}$ & $\mathrm{P}$ \\
Uterine length $(\mathrm{cm})$ & 5.5 & 6.7 & 5.2 & 4.5 \\
Endometrial echo $(\mathrm{mm})$ & 1.0 & - & - & - \\
Right ovary volume $\left(\mathrm{cm}^{3}\right)$ & 8.8 & 5.5 & 1.9 & - \\
Left ovary volume $\left(\mathrm{cm}^{3}\right)$ & 3.2 & 5.1 & 3.1 & 5.6 \\
\hline
\end{tabular}

Zoladex LA injections were given every 12 weeks.

$\mathrm{C}$, cylindrical (mid-childhood shape with cervix and fundus approximately the same); $\mathrm{P}$, pear shaped (adult shape with fundus larger than cervix).

Suppressive treatment was instituted in the five girls with early puberty in view of compounding factors of familial short stature $(\mathrm{n}=2)$ or rapid progression of puberty $(n=2)$, which would compromise final height and emotional immaturity $(n=1)$. Ten girls had been on suppressive treatment before commencing Zoladex LA (Zoladex $3.6 \mathrm{mg}$ $(\mathrm{n}=8)$ or Leuprorelin $3.75 \mathrm{mg}$ (Prostap SR; Wyeth $\mathrm{n}=2)$ ). The injection frequency was every three to four weeks and the median duration of treatment was 1.5 (range, $0.2-5.6$ ) years in these girls. Two girls (patients 6 and 11) were starting treatment de novo. The median ages at clinical diagnosis, start of treatment with $\mathrm{GnRH}$ analogue, and start of treatment with Zoladex LA were 7.3 (range, 1.8-9.9) years, 7.5 (range, 1.8-10.5) years, and 8.8 (range, 5.1-10.8) years, respectively. At the time of writing, the median duration of treatment with Zoladex LA was 1.2 (range, $0.6-1.4$ ) years in 11 of the 12 girls.

A reduction in growth rate was noted in nine girls after treatment with Zoladex LA (pretreatment heights were unavailable for the two girls treated de novo). Mean annual height velocities were as follows: pretreatment 6.5 (range, $3.8-9.6$ ) $\mathrm{cm} /$ year; post-treatment 4.5 (range, $3.1-6.6) \mathrm{cm} /$ year. The mean rate of skeletal maturation was normalised in 10 girls for whom data were available (change in bone age/ change in chronological age $(\Delta \mathrm{BA} / \Delta \mathrm{CA})=1.1$ years), although the range was relatively wide at $0-3.1$ years. Tables $2-12$ show pelvic ultrasound and pubertal staging results for 11 patients.

Breast development remained the same throughout the study in two girls, waxed and waned in five girls, and progressed in four girls. No regression of breast stage occurred. Uterine length was consistently greater than the mean for age in four girls, while in two others (patients 5 and 6) it was above average in five out of six and six out of seven cycles of treatment, respectively. There was poor correlation between breast and uterine development. An age appropriate cylindrical uterine configuration was either attained or maintained in eight of the 11 girls during the course of our study. Interestingly, three girls regressed to the infantile uterine configuration during the course of our study, but only the youngest (patient 4) has maintained this stage over several cycles of treatment. 
Table 10 Pelvic ultrasound results and breast stages for patient 9

\begin{tabular}{lllllllll}
\hline \multicolumn{1}{c}{ Cycle of Zoladex LA treatment } \\
\cline { 2 - 8 } & 0 & 1 & 2 & $3 *$ & 4 & 5 & 6 \\
\hline Age (years) & 10.7 & & & 11.4 & & & 12.0 \\
Breast stage & $3+$ & $3+$ & $3+$ & $4+$ & 5 & 5 & 5 \\
Uterine shape & C & C & - & C & C & - & C \\
Uterine length $(\mathrm{cm})$ & 3.4 & 3.7 & - & 3.6 & 3.9 & - & 3.9 \\
Endometrial echo $(\mathrm{mm})$ & - & - & - & 1.0 & - & - & - \\
Right ovary volume $\left(\mathrm{cm}^{3}\right)$ & 3.0 & 1.8 & - & 3.9 & 3.2 & - & 3.3 \\
Left ovary volume $\left(\mathrm{cm}^{3}\right)$ & 3.7 & 3.3 & - & 4.6 & 1.5 & - & 3.5 \\
\hline
\end{tabular}

Zoladex LA injections were given every 12 weeks.

${ }^{\star}$ Changed to injections every 10 weeks.

C, cylindrical (mid-childhood shape with cervix and fundus approximately the same).

Table 11 Pelvic ultrasound results and breast stages for patient 10

\begin{tabular}{llllllll}
\hline \multicolumn{7}{l}{ Cycle of Zoladex } & \multicolumn{2}{l}{ A treatment } \\
\cline { 2 - 8 } & 0 & 1 & 2 & 3 & 4 & 5 & 6 \\
\hline Age (years) & 10.8 & & & & & & 12.2 \\
Breast stage & $3+$ & $3+$ & $4+$ & 3 & 3 & 3 & 3 \\
Uterine shape & $\mathrm{C}$ & $\mathrm{P}$ & $\mathrm{C}$ & $\mathrm{C}$ & $\mathrm{I}$ & $\mathrm{I}$ & $\mathrm{C}$ \\
Uterine length (cm) & 3.3 & 4.0 & 4.0 & 3.9 & 3.4 & 3.4 & 3.2 \\
Endometrial echo $(\mathrm{mm})$ & - & - & - & - & - & - & - \\
Right ovary volume $\left(\mathrm{cm}^{3}\right)$ & 1.6 & 0.9 & 2.6 & 1.2 & 0.9 & 1.2 & 2.5 \\
Left ovary volume $\left(\mathrm{cm}^{3}\right)$ & 1.5 & 1.6 & 3.0 & 1.4 & 1.8 & 0.9 & 3.0 \\
\hline
\end{tabular}

Zoladex LA injections were given every 12 weeks.

I, infantile (cervix larger than fundus); C, cylindrical (mid-childhood shape with cervix and fundus approximately the same); $\mathrm{P}$, pear shaped (adult shape with fundus larger than cervix).

Table 12 Pelvic ultrasound results and breast stages for patient 11

\begin{tabular}{|c|c|c|c|c|}
\hline & \multicolumn{4}{|c|}{ Cycle of Zoladex $L A$ treatment } \\
\hline & 0 & 1 & 2 & 3 \\
\hline Age (years) & 10.5 & & & 11.2 \\
\hline Breast stage & 4 & $3+$ & $3+$ & 4 \\
\hline Uterine shape & $\mathrm{P}$ & $\mathrm{C}$ & $\mathrm{C}$ & $\mathrm{C}$ \\
\hline Uterine length $(\mathrm{cm})$ & 5.2 & 4.0 & 4.7 & 4.9 \\
\hline Endometrial echo (mm) & 1.0 & - & - & - \\
\hline Right ovary volume $\left(\mathrm{cm}^{3}\right)$ & 4.4 & 4.0 & 3.1 & 5.0 \\
\hline Left ovary volume $\left(\mathrm{cm}^{3}\right)$ & 3.4 & 2.4 & 3.2 & 7.2 \\
\hline
\end{tabular}

Zoladex LA injections were given every 12 weeks.

$\mathrm{C}$, cylindrical (mid-childhood shape with cervix and fundus approximately the same); $P$, pear shaped (adult shape with fundus larger than cervix).

Uterine length and shape proved reliable indicators of pubertal status, with obvious progression in two of three girls who required injections every nine or 10 weeks. All three of these girls also showed ovarian enlargement. However, there was great variation in ovarian volume in the study group as a whole, both between individuals and within individuals, and only one (patient 5) showed evidence of multicystic morphology (defined as at least six follicles of $\geqslant 4 \mathrm{~mm}$ diameter in each ovary ${ }^{13}$ ). A midline endometrial echo was present in three patients at the beginning of the study, in the three patients who were insufficiently suppressed and required more frequent injections, and in another patient who remained otherwise adequately suppressed throughout the study.

Overall, eight of the 12 girls were considered to be suppressed adequately on injections given at 12 week intervals. Of these, two (patients 8 and 11) stopped treatment after three cycles, at ages 11.0 (BA 13.3) and 11.2 (BA 13.2) years, respectively, at parental request. The three girls who needed more frequent injections reported clinical signs and symptoms of mood swings $(n=3)$, vaginal discharge $(n=1)$, abdominal pain $(n=1)$, and body odour $(n=1)$, reinforcing their pelvic ultrasound data.

One girl with autism experienced extreme mood swings, abdominal pain, and clinical progression of puberty eight weeks after her first injection, and was removed from the study at parental request. Treatment was changed to Zoladex $3.6 \mathrm{mg}$, given at 3 week intervals by her general practitioner. After seven months, she experienced vaginal bleeding, and pubertal progression was confirmed by pelvic ultrasound. Continuation of this treatment regimen for a further six weeks, with injections given in hospital, resulted in improvement of clinical symptoms with no further menstruation. Thereafter, Zoladex LA treatment, given at 10 week intervals, was reinstated with no deterioration in ultrasonic appearances or clinical signs of puberty. Administration of the depot preparation is extremely difficult in this patient as she does not keep still. We postulate that loss of pubertal suppression was a result of the depot not having been inserted deeply enough and slipping out.

No serious adverse effects occurred during our study. Possible associated events reported were: headache $(n=1)$, transient rash $(n=1)$, fatigue $(\mathrm{n}=1)$, and "flu-like" symptoms $(\mathrm{n}=1)$.

\section{Discussion}

Precocious puberty is a distressing condition for patients and their families and provision of a simple and effective form of treatment is beneficial. Depot preparations of GnRH analogue are simple to administer, and should be painless if given after the application of a local anaesthetic cream. We have found that the fear of receiving such a large injection can be greatly alleviated by distraction techniques.

Zoladex LA offers the advantage of less frequent injections. Most of our study group remained controlled on injections given at 12 week intervals, with only three requiring more frequent treatment every nine to 10 weeks. In keeping with previous work, ${ }^{14}$ we have found that some girls with precocious puberty are difficult to suppress and that the completely prepubertal state is seldom achieved. Partial suppression of puberty rather than complete regression appears to be a more realistic aim of treatment.

Maximisation of growth potential is an important factor influencing the decision of whether to treat girls with central precocious puberty, particularly those with below average target heights. Recent studies following girls treated with $\mathrm{GnRH}$ analogues to final height have shown promising results. For example, Brauner and colleagues ${ }^{15}$ found a direct correlation between final height and target height in 18 of 19 girls treated previously with triptorelin for a minimum of two years, while Oostdijk and colleagues ${ }^{16}$ reported that $62 \%$ of girls treated with the same GnRH analogue for 3.4 years attained final heights within their target range. It is our intention to follow our study group to final height, and it is encouraging to note the normalisation of growth rate and bone age advance during treatment with Zoladex LA. 
Clinical symptoms such as mood swings, abdominal pain, and vaginal discharge correlated with uterine morphology and were reliable indicators of pubertal progression. In contrast, breast development and ovarian morphology were less helpful signs. We were impressed by the accuracy of parents' ability to detect incomplete suppression in their daughters, merely by their behaviour, with "moodiness" being the most frequently quoted symptom.

Of the three girls who required more frequent injections, two completed three cycles of treatment before pubertal advance occurred. The third (patient 5) had very early onset precocious puberty (age 1.8 years) and has proved extremely difficult to suppress adequately. Injections at 10 week intervals were commenced but, subsequently, she required injections every nine weeks to achieve satisfactory control. Currently, no patient has needed injections at an interval of less than nine weeks.

We conclude that Zoladex LA is an effective treatment for girls with precocious or early puberty and recommend the following protocol:

- Careful clinical history and pelvic ultrasound scans at eight, 10 , and 12 weeks for at least two "cycles" of treatment to establish the optimum frequency of injections for individual patients

- Thereafter, pelvic ultrasound scanning should be performed at the time of injection to monitor efficacy of treatment.

This study was carried out independently, with the approval of, but no financial assistance from, Zeneca Pharma.
1 Crowley WF Jr, Comite F, Vale W, et al. Therapeutic use of pituitary desensitisation with a long-acting LHRH agonist: potential new treatment for idiopathic precocious puberty. F Clin Endocrinol Metab 1981;52:370-2.

2 Wheeler MD, Styne DM. Drug treatment in precocious puberty. Drugs 1991;41:717-28.

3 Breyer P, Haider A, Pescovitz OH. Gonadotropin-releasing hormone agonists in the treatment of girls with central precocious puberty. Clin Obstet Gynecol 1993;36:764-72.

4 Merke DP, Cutler GB. Evaluation and management of precocious puberty. Arch Dis Child 1996;75:269-71.

5 Bassi F, Serio M. Trattamento con agonista LH-RH (Zoladex depot) in soggetti affetti da puberta precoce. Drugs Exp Clin Res 1990;XVI(suppl):33-7.

6 Rangasami JJ, Grant DB. Familial precocious puberty in girls. FR Soc Med 1992;85:497-8.

7 Thomas BC, Stanhope R, Leiper AD. Gonadotrophin releasing hormone analogue and growth hormone therapy in precocious and premature puberty following cranial irradiation for acute lymphoblastic leukaemia. Horm Res 1993;39:25-9.

8 Griffin IJ, Cole TJ, Duncan KA, Hollman AS, Donaldson MDC. Pelvic ultrasound measurements in normal girls. Acta Paediatr 1995;84:536-43.

9 Kauli R, Pertzelan A, Ben-Zeer Z, et al. Treatment of precocious puberty with LHRH analogue in combination with cyproterone acetate-further experience. Clin Endocrinol 1984;20:377-87.

10 Tanner JM, Whitehouse RH, Cameron N, Marshall WA, Healy MJR, Goldstein H. Assessment of skeletal maturity and prediction of adult height (TW2 method). 2nd ed. London: prediction of adult height

11 Tanner JM. Growth at adolescence. 2nd ed. Oxford: Blackwell Scientific Publications, 1962

12 Griffin IJ, Cole TJ, Duncan KA, Hollman AS, Donaldson MDC. Pelvic ultrasound findings in different forms of sexual precocity. Acta Paediatr 1995;84:544-9.

13 Stanhope R, Adams J, Jacobs HS, Brook CJD. Ovarian ultrasound assessment in normal children, idiopathic precocious puberty, and during low dose pulsatile gonadotrophin releasing hormone treatment of hypogonadotrophic hypogonadism. Arch Dis Child 1985;60:116-19.

14 Donaldson MDC, Stanhope R, Lee TJ, Price DA, Brook CGD, Savage DCL. Clin Endocrinol 1984;21:499.

15 Brauner R, Adan L, Malandry F, Zantleifer D. Adult height in girls with idiopathic true precocious puberty. 7 Clin in girls with idiopathic true precoci
Endocrinol Metab 1994;79:415-20.

16 Oostdijk W, Rikken B, Schreuder S, et al. Final height in central precocious puberty after long term treatment with a slow release GnRH agonist. Arch Dis Child 1996;75: $292-7$ 